\title{
The Recall and New Job Search of Laid-off Workers: A Bivariate Proportional Hazard Model with Unobserved Heterogeneity
}

\author{
Bruce Fallick \\ Federal Reserve Board \\ Washington, D.C. 20551 \\ Telephone: 202-452-3722 \\ Fax: 202-452-5296 \\ E-mail: Bruce.Fallick@frb.gov \\ and \\ Keunkwan Ryu \\ Department of Economics \\ Seoul National University \\ and Department of Economics \\ Hong Kong University of Science and Technology \\ E-mail: ryu@snu.ac.kr \\ Original version November 1997 \\ this version March 2003
}

\begin{abstract}
Workers who lose their jobs can become re-employed either by being recalled to their previous employers or by finding new jobs. Workers' chances for recall should influence their job search strategies, so the rates of exit from unemployment by these two routes should be directly related. We solve a job search model to establish, in theory, a negative relationship between the recall and new job hazard rates. We look for evidence in the PSID by estimating a semi-parametric competing risks model with explicitly related hazards. We find only a small negative behavioral relationship between recall and new job hazard rates.
\end{abstract}

KEY WORDS: Lay-off; Recall; Job search; Hazard rate; Proportional hazard model; Unobserved heterogeneity; Duration dependence.

JEL Classification Number: J64, C41

Keunkwan Ryu would like to acknowledge financial support of the Korea Research Foundation. The views expressed are those of the authors and do not necessarily represent those of the Board of Governors or the staff of the Federal Reserve System. 


\section{Introduction}

Workers who lose their jobs can become re-employed either by being recalled to their previous employers or by finding new jobs. Each of these routes out of unemployment has merited the attention of researchers interested in how quickly job losers return to employment. Although intuition, as well as casual observation, suggests that workers' prospects for being recalled should influence how hard they search for new jobs (including which offers they are willing to take), the empirical literature on the topic has generally proceeded without taking explicit account of this interaction.

Katz (1986) recognized that the negative duration dependence observed in the overall rate of exit from unemployment could be due partly to negative duration dependence in the recall hazard masking positive dependence in the new job hazard. He estimated a competing risks duration model that allowed for both routes out of unemployment, assuming independent Weibull hazard functions and no unobserved heterogeneity, and found positive duration dependence in the new job hazard. (See also Pichelmann and Riedel 1992.)

Han and Hausman (1990) demonstrated that the Weibull assumption was overly restrictive. They estimated a semi-parametric competing risks model with a flexible baseline hazard function. In addition, they allowed the two types of risks to be interrelated. While they found no statistically significant relationship between the two hazard rates, they did find that with their more flexible specification, there was no evidence of positive duration dependence in the new job hazard.

However, Han and Hausman did not take into account unobserved heterogeneity as such, nor did it attempt to explicitly incorporate the behavioral interaction between the two routes out of unemployment.

In this paper, we propose an improved specification that incorporates both these features. We solve a job search model in order to establish, theoretically, a negative behavioral relationship between the recall and the new job hazard rates that stems from the optimal search strategy of the worker. We then estimate a semiparametric duration model with two competing risks, allowing for both observed and unobserved heterogeneity and for a behavioral relationship between the two risks. We find positive duration dependence in the new job hazard function, but only a small negative behavioral relationship between the recall and new job hazards.

Like the current work, both Katz (1986) and Han and Hausman (1990) estimated the objective probability of recall, but lacked any direct measure of workers' subjective probabilities of recall. In contrast, Katz and Meyer (1990) and Anderson (1992) estimated competing risks models in which self-reported recall expectations enter the new job hazard function as a covariate. Both studies found that workers' initial expectations of recall severely depressed the rate at which workers found new jobs, and that this effect diminished over the course of a spell of unemployment. We view this research and our own work, in which we infer recall expectations from 
observed recall rates, as alternative approaches to answering this question. Each approach has its advantages. On the one hand, data on recall expectations allow workers' subjective probabilities (which drive search behavior) to differ from observed probabilities, and do not suffer from quite the difficulties of identification that will be an issue in our work. On the other hand, currently available data sets that include a measure of recall expectations are limited in scope (for example, including only recipients of unemployment insurance benefits), include only binary measures of recall expectations, and measure these expectations only at the beginning of the spell, with little indication of how those subjective probabilities may change as the spell progresses. Moreover, given the survey question, it is not clear just what is meant when a repondent says that she "expects" to be recalled. Both the level of confidence and the time frame in which she expects to be recalled are ambiguous, which makes interpretation difficult. (See section 7.)

\section{Identifying the Behavioral Relationship}

Section 3 below presents a theoretical model of job search. Taking into account his chances for recall, an unemployed worker chooses how much effort to put into searching for a new job, and how choosy to be. If he takes a new job too early, he sacrifices the chance of returning to his previous employer. But the longer he waits before taking a new job, the more income he foregoes. The model characterizes the search starting time, search intensity, and the reservation wage partly as functions of the unemployed worker's prospects for recall.

We then move on to estimate the joint distribution. The observed unemployment duration will be the minimum of the time to recall and the time to accepting a new job. We assume that the worker cannot affect her probability of being recalled, except by accepting a new job. Thus, the time to recall is exogenous, but the time to accepting a new job is endogenous and influenced by the prospects for recall. Thus, the observed duration is most suitably characterized by a dependent competing risks duration model.

However, although the behavioral relationship between the two risks may be clear in theory, in practice the observed relationship between the recall and new job hazard rates may stem from another source: the direct effect of heterogeneity across individuals. If one believes that "better" workers will be quicker than "poorer" workers both to be recalled and to find new jobs, then the relationship between the two hazard rates induced directly by heterogeneity should be positive. If, instead, prospective new employers are reluctant to hire wrokers laid off from the types of jobs that tend to engage in temporary layoffs and subsequent recalls, then the relationship between the two hazard rates induced directly by heterogeneity should be negative. In either case, the behavioral relationship should be negative.

To identify these two different relationships empirically is not easy. Conceptually, the negative behavioral relationship applies to a given laid-off worker as her 
chances for recall change over the course of her unemployment spell, or to a set of workers who are identical except for the recall probabilities they face, whereas the directly-heterogeneity-induced relationship applies across different (non-identical) laid-off workers. In data comprising single spells for many different workers - the sort of data a researcher typically confronts - the two types of relationship are confounded.

Moreover, in such data, the non-behavioral (so to speak) heterogeneity-induced relationship is likely to dominate the negative behavioral relationship. Consequently, in order to test for the negative behavioral relationship implied by theory, one needs to carefully control for heterogeneity, both measured and unmeasured. In this paper, we control for observed heterogeneity by including a rich set of covariates, and control for unobserved heterogeneity using discrete methods suggested by Heckman and Singer (1984).

Yet the difficulties in identifying the behavioral relationship may be more subtle still. The negative behavioral relationship between the two hazards should manifest itself in two ways: through the dependence of the overall level of an individual's new job hazard on the overall level of the individual's recall hazard, and through the dependence of the change in his new job hazard over the course of an unemployment spell on the change in his recall hazard over the course of the same spell. The distinction is reminiscent of between-group variation vs. within-group variation in the standard decomposition of variance, if one interprets a group as the weeks constituting an individual spell of unemployment.

Since our data generally do not include multiple spells for the same individual, the first manifestation of behavioral relationship - that between the overall levels and the spurious relationship induced by heterogeneity both show up in comparisons across different individuals. It may, consequently, be difficult in practice to distinguish between the two. The second manifestation of the behavioral relationship that over time within a spell - is more distinct.

The variation in recall hazards over time within a spell of unemployment is apparently much smaller than the cross-sectional variation in overall recall hazards. For example, across persons recall prospects can and do vary from clearly zero, as in the case of business closings, to almost certain with a recall date specified in advance by the employer, as one often sees, say, in the auto industry. Accordingly, we see a trade-off in empirically identifying the behavioral relationship: The negative behavioral relationship induced by the variation over time in recall hazards is not confounded by any competing heterogeneity effect, but may not assert itself so strongly in the data; whereas the relationship induced by cross-sectional variation in the overall levels of the hazard rates is more muddled, in the sense that it combines a "behavioral" relationship with a directly heterogeneity-induced relationship, but because of the large amount of variation in recall prospects across individuals, it probably has a much stronger presence in the data.

Our estimation procedure is designed to try to separate the two sources of cross-sectional variation, and then combine the behavioral source of cross-sectional 
variation with the behavioral over-time variation. The two behavioral sources are combined in that, at a given point in a spell of unemployment, a person will search for new job with (presumably) greater intensity if he faces a lower recall hazard regardless of whether the latter is due to the dissipation of his chances for recall as time passes, or due to his "inferior" individual or job characteristics to begin with. This compromise is consistent with the semi-Markov property established in the theory, that is, a laid-off worker's optimal search strategy at any time is a function of the level of the recall hazard rate at that time, without regard to the path by which that level was arrived at.

To control for the "non-behavioral" relationship between the two hazard rates induced directly by heterogeneity, we allow observed and unobserved individual and job characteristics to enter both the new job and recall hazards in the form of a proportionality term in each hazard function. The proportionality assumption reflects the idea that "better" workers are viewed by the previous employer as well as potential new employers as better prospects than "poorer" workers throughout the unemployment spell. Within each proportionality term, measured and unmeasured individual differences are captured through covariates and through a pair of random variables, respectively.

Once we control for non-behavioral relationship between the new job and recall hazards generated by measured and unmeasured individual differences through the proportionality term in each hazard function, we hope to be able to identify the behavioral negative relationship between new job hazard rates and recall hazard rates that should obtain both over the course of an unemployment spell for a given individual and across otherwise similar individuals facing different recall prospects. This behavioral relationship is captured by allowing the recall hazard to influence the new job hazard directly. The remaining pattern, captured through baseline hazard rates, is supposed to represent the evolution of the hazards over the course of an individual's unemployment spell, which is assumed to be common to all individuals.

Of the literature that has attempted to estimate these hazard rates, our econometric framework is closest to that used by Han and Hausman (1990), but differs in three important respects. First, we introduce unobserved heterogeneity along the lines of Heckman and Singer (1984), whereas Han and Hausman, relying on the evidence of their single-risk estimates, chose not to include unobserved heterogeneity in their competing risks model. Second, we remain loyal to the initial mixed proportional hazard specification, whereas Han and Hausman deviated from their initial model in the competing risks setting by assuming that certain transformations of $T_{1}$ and $T_{2}$ follow a bivariate normal distribution, thus avoiding the bivariate extreme value distribution which would naturally follow from the initial assumption of the proportional hazard model. Third, and most important, our model specification allows us to test for the behavioral relationship between the two risks implied by the theory. Our model is logically consistent, and is also tractable to estimate.

In sum, our paper attempts to make several contributions: Methodologically, (i) both theory and estimation are handled consistently, (ii) methods of identifying 
behavioral relationships between the recall and new job hazard rates are proposed, and (iii) our empirical model improves upon those of Katz's and Han-Hausman's. Substantively, (iv) we show the new job hazard to be increasing, and (v) we find evidence of an economically small negative behavioral relationship between the recall and new job hazards, leaving in some doubt the negative influence of recall prospects on new job search behavior.

\section{Theoretical Model}

One can characterize a laid-off worker's optimal search strategy as a trade-off between waiting for recall and searching for a new job. Intuitively, if the probability of recall is sufficiently high, it is better not to search for a new job at all and simply to wait for recall. But, over time, as the chance of recall (presumably) falls, even such a worker will start trying to generate new job offers. This search activity becomes more intense as the probability of recall shrinks, reaching a maximum when there is no chance of recall at all.

This characterization of the optimal search strategy is a solution to the stochastic optimal control problem that trades-off the conflicting objectives of, on the one hand, minimizing search costs and preserving human capital, and on the other hand, minimizing the length of the unemployment spell and thus reducing the earnings foregone. To characterize this optimal search strategy, we first need to make assumptions about the exogenous stochastic process governing the distribution of the time to recall. Then we can characterize the optimal behavior of the laid-off worker. This characterization plays an important role in deriving the joint distribution of the time to recall and the time to finding a new job.

First we introduce notation:

$w=$ deterministic wage rate prevailing at the previous job;

$W_{j} \sim F(\cdot)=$ random wage rate at a new job;

$r(t)=$ recall hazard rate after time $t$ has elapsed since lay-off, $r^{\prime}(t) \leq 0^{1}$;

$s \in S$ =search intensity of a laid-off worker, $S \subset R^{+}$;

$c(s)=$ cost of searching as a function of search intensity,

$c(0)=0, c^{\prime}(s)>0, c^{\prime \prime}(s) \geq 0$

$\lambda(s)=$ new job arrival rate as a function of search intensity, $\lambda^{\prime}(s)>0, \lambda^{\prime \prime}(s)<0$;

$\delta=$ discount rate;

$T_{r}=$ time (duration) until recall;

$T_{j}=$ time (duration) until accepting a new job;

$T \equiv \min \left(T_{r}, T_{j}\right)=$ duration of unemployment for a laid-off worker.

The recall hazard rate $r(t)$ determines the time to recall $T_{r}$. We assume here

1 The hazard rate is also referred to in the literature as the failure rate or the age specific death rate. 
that the recall hazard rate $r(t)$ is monotonically decreasing, $r^{\prime}(t) \leq 0$. Whether or not one searches for new job, and, if one does search, how much search effort one puts forth, determine the cost of search and the arrival rate of new job offers. The cost of searching, $c(s)$, is an increasing function of the search intensity $s, s \geq 0$, with increasing marginal cost. The benefit of searching is generating new job offers. New jobs arrive according to a non-homogeneous Poisson process with intensity $\lambda(s)$. This arrival rate $\lambda(s)$ is an increasing function of $s$. But the marginal benefit of search in terms of the marginal increase in the new job arrival rate is assumed to be decreasing in s. The new job arrival rate and the reservation wage level (to be defined below) will determine the hazard rate for finding a new job, and thus the duration $T_{j}$ leading to accepting a new job.

Between the two competing duration variables, $T_{r}$ and $T_{j}$, only the minimum, $T=\min \left(T_{r}, T_{j}\right)$ is realized and observed, with its source identified.

Given his discount rate $\delta$, a laid-off worker maximizes expected discounted future income from time zero to infinity by pursuing an optimal search strategy. The choices open to the worker at each instant are whether or not to search for a new job, how much effort to put into the search activity, and whether to take a new job once offered.

The optimal search strategy determines the time until a new job $T_{j}$ endogenously. Given the infinite horizon and the stationarity of other elements of the search problem, the environment is stationary conditional on the recall hazard rate. Of course, the recall hazard rate itself is decreasing over time, introducing an element of unconditional non-stationarity. Thus, not conditional on the recall hazard rate, the optimal search strategy changes over time, but once the recall hazard rate is given, the optimal search strategy can be characterized purely as a function of the recall hazard rate, independent of the time elapsed since lay-off. In this way, the optimal job search strategy satisfies a semi-Markov property, a property crucial for empirical identification of the behavioral relationship.

Let us formalize some of the above statements into assumptions:

Assumption 1. The recall hazard rate is monotonically decreasing for each laid-off worker, $r^{\prime}(t) \leq 0$.

In the empirical analysis, we will estimate $r(t)$ without imposing this monotonicity assumption, and then test whether the estimated pattern is consistent with the monotonicity assumption.

Assumption 2. A new job, once turned down, cannot be "recalled" later on (search without "recall").

Note that here we write "recall" with quotation marks. This "recall", as used in the literature, means an option to accept previous job offers at a later time, and is an altogether different concept from the recall to the previous job that we are analyzing in this paper. In the traditional stationary search model, such as Lippman and McCall (1976a,b), search with "recall" and search without "recall" result in 
the same optimal search strategy on the part of the worker: Under stationarity, a rational economic agent has no reason to revise his previous accept/reject decision, implying that an offer once turned down will never be "recalled." Therefore, the option of "recall" will never be exercised, and there is no difference between the search strategies with and without "recall."

But here, the chance of being recalled to one's previous employer is decreasing over time, introducing non-stationarity into the environment, and causing search with "recall" to differ from search without "recall." Through Assumption 2, we restrict our consideration to the search without "recall." However, the main point of the model - that the new job hazard should be decreasing in the recall hazard - would obtain without this assumption, and our empirical specification does not embody this assumption.

Assumption 3. An offer to be recalled is always accepted.

Assumption 3 says that value of recall is higher than the value of continuing to search, at any level of the recall hazard rate. This condition is more likely to be satisfied as the wage prevailing at recall is higher relative to the expected wage at new jobs, as the new job wage distribution has less variation, as the discount rate increases, and as the new job arrival rate decreases.

In practice, an offer of recall may not always be accepted, and in our data, we cannot identify whether a worker has received and declined an offer of recall before taking a new job. However, in our judgment the probability that a worker will turn down recall is low. So, for simplicity, we adopt Assumption 3 in our model. It would be interesting to extend the model by relaxing this assumption, but that is beyond the scope of the current work.

Once a new job offer arrives, the unemployed worker evaluates the offered wage rate. If it is high enough, he will take the new job. Otherwise, he will turn down the offer, and continue searching for another new job while also waiting for recall. In contrast, by assumption 3, a laid-off worker will always accept an offer of recall.

Assumption 4. The cost function $c(s)$ is increasing from an initial level of zero and is convex with respect to search intensity $s: c(0)=0, c^{\prime}(s)>0, c^{\prime \prime}(s) \geq 0$. The new job arrival rate function $\lambda(s)$ is increasing but at a decreasing rate: $\lambda^{\prime}(s)>$ $0, \lambda^{\prime \prime}(s)<0$. A new job offers a random wage $W$ which is distributed according to a distribution function $F(\cdot)$. Wages are independent across offers.

Assumption 4 posits the typical positive and increasing marginal cost function $c^{\prime}(s)$, and the typical positive but decreasing marginal product function $\lambda^{\prime}(s)$. Wage offers are assumed i.i.d. according to a distribution function $F(\cdot)$.

Under these assumptions, one can show that the optimal search strategy of an unemployed worker over time is characterized by Theorem 1, and that one unemployed worker's optimal search intensity is different from another's when the two are faced with different recall hazard rates, as stated in Theorem 2. 
Theorem 1. (search strategy of an unemployed worker over time) The optimal search strategy is characterized by nondecreasing search intensity and nonincreasing reservation wage, leading to a nondecreasing new job hazard rate over the duration of an unemployment spell. If the initial recall hazard rate is high enough, it is optimal not to search for a new job at all until a certain amount of time has elapsed since lay-off. Because the recall hazard rate is decreasing over time, a laid-off worker will increase search effort over time, and will accept any new job offering a wage higher than the reservation wage at that time. The reservation wage is nonincreasing over time, reflecting the fact that the laid-off worker is more willing to accept new jobs as the recall hazard rate falls. (proof in the appendix)

Theorem 2. (comparison of two unemployed workers' search behavior) Suppose that there are two unemployed workers, say $A$ and $B$, where $A$ is faced with a uniformly higher recall hazard rate schedule than $B$ over the course of their unemployment spells. Then, A will begin to search for a new job later in the spell than will $B$. At any point in the spell at which both $A$ and $B$ are searching for new jobs, $A$ will search less intensely than $B$. (proof in the appendix)

These two theorems allow us to identify the behavioral relationship between the recall hazard and the new job hazard in empirical implementation.

\section{Empirical Model}

Our task is to develop an empirical model that allows one to test whether recall hazard rates are decreasing, whether new job hazard rates are increasing, and whether recall hazards depress new job hazards.

However, as described in section 2, there are differences across workers in characteristics and circumstances that cause their hazard rates to move together in a non-behavioral way. For example, a worker disemployed during a boom may face a higher recall probability, and also will find a new job more easily, than an otherwise identical worker disemployed during a recession. To take an opposite example, a worker with a large amount of firm-specific human capital may face higher recall but lower new job hazard rates than a worker with more general skills. Thus heterogeneity can generate a spurious (with respect to the theory) cross-sectional relationship, either positive or negative, between the recall and new job hazard rates.

If we observed many unemployment spells for each individual, it would be easier to identify the negative relationship between the two hazards rates. However, as is typically the case, in our data we observe many individuals for only one spell (and often only part of that). Under these circumstances, the spurious positive relationship between the hazards across individuals may dominate the negative behavioral relationship, resulting in a positive overall observed relationship. The nature of the data, then, requires careful attention to be paid to heterogeneity, both measured and unmeasured, if we hope to uncover the negative behavioral 
relationship.

The trick is to find a way to separately identify the spurious cross-sectional relationship arising directly from heterogeneity from the behavioral relationship that arises from the worker's reaction to that heterogeneity. In the empirical model presented below, we employ essentially two identifying assumptions, beyond the standard assumptions of the proportional hazard model.

First, we allow individual heterogeneity, measured and unmeasured, to generate any pattern of cross-sectional relationships between the two hazard rates by letting individual and job characteristics enter into the recall and new job hazard functions with free coefficients, and by introducing random variables representing unobserved heterogeneity into both hazard functions without restricting their correlation across the hazards. However, we allow only a single combined effect of the recall hazard rate on the new job hazard rate, since it is only this total recall hazard, not its individual determinants, that ought to influence new job search behavior.

Second, we assume that workers unemployed due to plant closings or to the ends of seasonal or temporary jobs have no recall prospects and are aware that they have none. Econometrically, this restriction serves the same purpose as the more typical exclusion restrictions in a two-equation system, by forcing these variables to have a larger impact on the recall hazard than on the new job hazard in a particular fashion determined by our prior knowledge of the world.

Let $z=\left\{z_{1}, z_{2}, \cdots\right\}$ denote a collection of observed individual and job characteristics affecting the recall and new job hazard rates in weeks $\{1,2, \cdots\}$ after the loss of a job. Let $e$ and $v$ denote two possibly correlated random variables capturing unmeasured heterogeneity in the recall and the new job hazard rates, respectively. $z$ controls for observed heterogeneity, whereas $e$ and $v$ are intended to account for remaining individual differences. Higher draws of $e$ and $v$ mean that the corresponding worker faces a better chance of recall and finding a new job, respectively.

Workers who lost their jobs due to plant closings or the end of seasonal or temporary jobs are assumed to face a recall hazard rate of zero throughout their unemployment spell (with a few exceptions, described in note 5 below). To distinguish these workers from those who may have recall prospects, we define an indicator variable $1_{\text {nohope }}$, which takes value one if the worker was dismissed due to either plant closing or end of seasonal or temporary job and zero otherwise. These workers will presumably start searching for new jobs immediately after becoming unemployed.

Consider a worker characterized by a vector $(z, e, v)$. We model the recall hazard rate of this worker as:

$$
r(t \mid z, e, v)=r(t \mid z, e)=\left(1-1_{\text {nohope }}\right) r_{0}(t) \exp \left(x_{t} \beta+e\right),
$$

where the value of $1_{\text {nohope }}$ can be determined from information in $z$, and $x_{t}$ is a subset of $z_{t}$ influencing the recall hazard rate at week $t$ for potentially recall-able workers. 
This specification has the form of a mixed proportional hazard model. The (mixed) proportionality part, $\left(1-1_{\text {nohope }}\right) \exp \left(x_{t} \beta+e\right)$, controls for observed and unobserved heterogeneity. The proportional hazard assumption reduces the duration dependence of recall hazard rate for each individual worker to the duration dependence of the common baseline hazard function, simplifying the task of testing assumptions about duration dependence. ${ }^{2}$

To anticipate our description of the data in section 5 , the observed heterogeneity term $z$ includes numerous socio-economic variables, year dummies, three region dummies, seven industry dummies, and five occupation dummies. Additionally, $z$ includes a dummy variable for whether the worker received unemployment insurance (UI) benefits, and its interaction with each of two benefit exhaustion points at 26 and 39 weeks. These interaction terms serve to control for spikes in the exit rates observed in our data for UI recipients (see Katz 1986 or Han and Hausman 1990).

A realization of $z$ and $e$ defines a conditional distribution of $T_{r}$ through the conditional recall hazard rate $r(t \mid z, e)$. From $f_{r}(t \mid z, e) / S_{r}(t \mid z, e)=r(t \mid z, e)$, we derive $S_{r}(t \mid z, e)=\exp [-R(t \mid z, e)]$, where $S_{r}(t \mid z, e)=\operatorname{Pr}\left(T_{r} \geq t \mid z, e\right)$ is the conditional recall survival function, $f_{r}(t \mid z, e)$ is the corresponding conditional recall density function, and $R(t \mid z, e)=\int_{0}^{t} r(u \mid z, e) d u$ is the integrated recall hazard rate. Note that $z$ will be observed both by the individual worker and econometricians, but $e$ will not be observed by the econometrician. Thus, we obtain an unconditional distribution of $T_{r}$ by taking the expectation of the above quantities with respect to the stochastic nature of $e: S_{r}(t \mid z)=E_{e} S_{r}(t \mid z, e)$.

In section 3 , we derived the new job hazard rate as a solution to an optimal control problem, given an exogenously specified recall hazard rate: the new job hazard rate is $\lambda(s(r)) \cdot\left[1-F\left(w_{r}^{*}\right)\right]$ when the recall hazard rate is $r$.

Note that the derived new job hazard rate, being the product of new job arrival rate and the probability that the offered wage exceeds the reservation wage, would not in general be in a proportional hazard form, even if, as we have assumed, the recall hazard rate is in a proportional hazard form. A fully structural approach would specify $\lambda(s)$ as a function of $s$, and characterize $s(r)$ and $w_{r}^{*}$ in terms of $r$. In this paper, we take a reduced-form approach (i) modeling the new job hazard rate as a function of the recall hazard rate as well as additional time and heterogeneity components, and then (ii) testing the structural search implications ex post. This approach allows us to specify the recall and the new job hazard rates flexibly at the sacrifice of theoretical neatness.

To capture the theoretical implication that the new job hazard rate "reacts" to the recall hazard rate, we explicitly model the new job hazard rate as a function of the recall hazard rate. Any other duration dependence in the new job hazard

2 Given the computational demands inherent in our model, one can easily imagine how difficult it would be to test for duration dependence for each individual without invoking the proportionality assumption. In section 6 we test the proportionality assumption using the methods in Ryu (1994), and fail to reject it. 
rate will be captured by a baseline hazard rate for new jobs. Thus we can test for any time pattern in the new job hazard rate that remains after controlling for the effect of changing recall hazard rate and the effects of measured and unmeasured heterogeneity. Specifically, we model the new job hazard rate as

$$
j(t \mid z, e, v)=j(t \mid z, v)=j_{0}(t) \exp \left(z_{t} \gamma+a \cdot\left(1-1_{\text {nohope }}\right) r_{0}(t) e^{x_{t} \beta}+v\right) .
$$

Observed heterogeneity appears anew in the new job hazard specification, with its own set of coefficients, as one would not expect the effects of worker and job characteristics on recall and new job finding to be the same. For example, union members may be more likely to be recalled, but less likely to find new jobs. If so, the union dummy variable will appear in the recall hazard rate with positive coefficient, but in the new job hazard rate with a negative coefficient. We allow for this differential impact for all variables. Also, to see whether job loss due to plant closing or end of seasonal or temporary jobs have an effect on speeding up new job search in addition to their influence via the recall hazard rate, we allow $z$ to include plant closing status and temporary/seasonal status in addition to variables in $x$. To control for unobserved heterogeneity in the new job hazard rate, we introduce another discrete random variable $v$, which may be correlated with $e$. The correlation between $e$ and $v$, if any, would reflect the spurious relationship between the recall and new job hazard rates arising from unmeasured heterogeneity.

The introduction of $a \cdot\left(1-1_{\text {nohope }}\right) r_{0}(t) e^{x_{t} \beta}$ as an argument in the new job hazard specification is intended to capture one of the major implications of the job search model developed in the previous section. We introduce this term under the assumption that agents know their overall recall chances - to the extent that it is determined by measured heterogeneity - and react to this knowledge when looking for new jobs. We assume that agents do not know the realization of $e$ and thus do not react to this term. This assumption is of course open to question, but is not critical for our results.

If $a$ turns out to be negative, it implies that a laid-off worker whose chance of recall is lower is, in response, more enthusiastic about finding a new job, and searches more intensely or with a lower reservation wage. The lower probability of recall may derive from the time that has elapsed since the lay-off, or from unfavorable individual or job characteristics; the result is the same. In the extreme case, workers who lost their jobs due to a plant closing or the end of a temporary job exhibit the strongest behavioral reaction because they have no chance of being recalled throughout their spells of unemployment.

In addition, we are interested in seeing whether $r_{0}(t)$ and $j_{0}(t)$ display any duration dependence of their own. If our job search theory is a reasonable description of behavior, then the behavioral relationship between the recall hazard rate and the new job hazard rate should be captured through the negative coefficient of $a$. But we have no particular expectation for a remaining temporal pattern in $j_{0}(t)$, once we control for $\left(1-1_{\text {nohope }}\right) r_{0}(t) e^{x_{t} \beta}$ in the specification of the new job hazard rate. 
To save on the number of parameters to be estimated, we restricted the recall and new job baseline hazard functions each to be a step function, with the number of steps considerably smaller than the number of weeks in the duration data. Also, to avoid odd behavior in the estimated baseline hazard functions due to the sparsity of observations at longer durations, we right-censored any observations whose reported duration is longer than or equal to 60 weeks. The lengths of the steps are identical for the two hazard functions. After considerable experimentation, we chose a step function with 12 steps: the first three steps are each 2 weeks long, the second three are each 3 weeks long, the third three are each 4 weeks long, and the final three are each 11 weeks long. The lengths of the steps are increasing because the data become sparser as duration increases. This choice appears to represent a good balance between flexibility and tractability.

Assuming that the baseline hazard functions are constant within each step but vary across steps, let us define $r_{k}$ and $j_{k}$ as $r_{k}=\log r_{0}(t)$ and $j_{k}=\log j_{0}(t)$ for time $t$ within step $\mathrm{k}, k=1, \cdots, 12$. Note that the $r_{k}$ 's and $j_{k}$ 's are unrestricted, whereas $r_{0}(t)$ and $j_{0}(t)$ are restricted to be positive. Then, $r_{1}, \cdots, r_{12}$ are twelve free parameters characterizing the recall baseline hazard function, and $j_{1}, \cdots, j_{12}$ are twelve free parameters characterizing the new job baseline hazard function. Thus, each baseline hazard function is approximated as a step function with twelve steps covering durations from one to sixty weeks. From (6) and (7), we have, for $k=1, \cdots, 12$,

$$
\begin{aligned}
& r(t \mid z, e)=\left(1-1_{\text {nohope }}\right) \exp \left(r_{k}+x_{t} \beta+e\right), \text { for } t \text { in step } k, \\
& j(t \mid z, v)=\exp \left(j_{k}+z_{t} \gamma+a\left(1-1_{\text {nohope }}\right) e^{r_{k}+x_{t} \beta}+v\right), \text { for } t \text { in step } k .
\end{aligned}
$$

Now, let us write down the likelihood contribution of each observation according to the duration and outcome of its unemployment spell. An observation will take one of the following three forms:

(i) An unemployment spell is terminated due to recall in the $t$ th time interval. In this case, we assign to the observation $\operatorname{Pr}\left(t-1<T_{r} \leq t, T_{j}>T_{r}\right)$, which will be bounded by $\operatorname{Pr}\left(t-1<T_{r} \leq t, T_{j}>t\right)$ and $\operatorname{Pr}\left(t-1<T_{r} \leq t, T_{j}>t-1\right)$. Since the length of an interval in our data is just one week and, accordingly, a worker's chance of receiving both a recall and an acceptable new job offer in the same interval is quite small, all three probabilities will be approximately equal. While the two bounds are easy to compute, the true probability is relatively involved to compute (see Han and Hausman 1990, Fallick 1991, McCall 1996). So, we approximate the true probability $\operatorname{Pr}\left(t-1<T_{r} \leq t, T_{j}>T_{r}\right)$ as $\operatorname{Pr}\left(t-1<T_{r} \leq t, T_{j}>t-1\right)$.

(ii) An unemployment spell is terminated due to taking a new job in the $t$ th time interval. In this case, we assign to the observation $\operatorname{Pr}\left(T_{r}>T_{j}, t-1<T_{j} \leq t\right)$, which will be bounded by $\operatorname{Pr}\left(T_{r}>t, t-1<T_{j} \leq t\right)$ and $\operatorname{Pr}\left(T_{r}>t-1, t-1<\right.$ $\left.T_{j} \leq t\right)$. We will approximate the true probability $\operatorname{Pr}\left(T_{r}>T_{j}, t-1<T_{j} \leq t\right)$ as $\operatorname{Pr}\left(T_{r}>t-1, t-1<T_{j} \leq t\right)$. 
(iii) An unemployment spell is still going on at the end of the $t$ th interval. In this case, we assign to the observation $\operatorname{Pr}\left(T_{r}>t, T_{j}>t\right)$.

As mentioned above, for those workers unemployed due to plant closings or the end of temporary or seasonal jobs, we assume that the probability of recall is zero throughout the unemployment spell. If such a spell is terminated due to taking a new job in the $t$ th time interval, we assign $\operatorname{Pr}\left(T_{r}>T_{j}, t-1<T_{j} \leq t\right)=\operatorname{Pr}(t-1<$ $\left.T_{j} \leq t\right)$ after imposing $r(u \mid z, e)=0$ for all $u$. On the other hand, if such a spell is still going on at the end of the $t$ th interval, we assign $\operatorname{Pr}\left(T_{r}>t, T_{j}>t\right)=\operatorname{Pr}\left(T_{j}>t\right)$.

To derive the probabilities in (i)-(iii) above from the hazard rates specified in $(8)$, it is useful to define the integrated hazard rates, $R(t \mid z, e)=\int_{0}^{t} r(u \mid z, e) d u$ and $J(t \mid z, v)=\int_{0}^{t} j(u \mid z, v) d u$, for the recall and the new job hazard rates, respectively. Assuming that $z$ is constant within each week (which is the case in our data), these integrations reduce to summations by virtue of the assumed step nature of the baseline hazard functions,

$$
\begin{aligned}
& R(t \mid z, e)=\sum_{u=1}^{t} r(u \mid z, e) \\
& J(t \mid z, v)=\sum_{u=1}^{t} j(u \mid z, v), t=0,1, \cdots, 60
\end{aligned}
$$

where $R(0 \mid z, e)=J(0 \mid z, v)=0$. The conditional survival probabilities are,

$$
\begin{aligned}
& S_{r}(t \mid z, e)=P\left(T_{r}>t \mid z, e\right)=\exp [-R(t \mid z, e)], \\
& S_{j}(t \mid z, v)=P\left(T_{j}>t \mid z, v\right)=\exp [-J(t \mid z, v)] .
\end{aligned}
$$

Recall that $T_{r}$ and $T_{j}$ are correlated through the search strategies of laid-off workers as well as through heterogeneity across workers. If our model is wellspecified, in the sense that these relationships are fully reflected in the specification of $r(t \mid z, e)$ and $j(t \mid z, v)$, then it is reasonable to assume that $T_{r}$ and $T_{j}$ are independent given $r(t \mid z, e)$ and $j(t \mid z, v)$.

Under this assumption of conditional independence, we have

$$
\begin{aligned}
\operatorname{Pr}\left(t-1<T_{r} \leq t, T_{j}>t-1 \mid z, e, v\right) & =\left[S_{r}(t-1 \mid z, e)-S_{r}(t \mid z, e)\right] \\
& \times S_{j}(t-1 \mid z, v) \\
\operatorname{Pr}\left(T_{r}>t-1, t-1<T_{j} \leq t \mid z, e, v\right) & =S_{r}(t-1 \mid z, e) \\
& \times\left[S_{j}(t-1 \mid z, v)-S_{j}(t \mid z, v)\right], \\
\operatorname{Pr}\left(T_{r}>t, T_{j}>t \mid z, e, v\right) & =S_{r}(t \mid z, e) S_{j}(t \mid z, v) .
\end{aligned}
$$

We do not observe the realization of $(e, v)$, so we must take the expectation of the above quantities with respect to the stochastic nature of $(e, v)$. Assume that $e$ and 
$v$ follow a discrete bivariate distribution that takes value $\left(e_{l}, v_{m}\right)$ with probability $p_{l m}, l=1, \cdots, M$ and $m=1, \cdots, M$. Here, $M$ denotes the number of support points for each of $e$ and $v$. This approach has been advocated by Heckman and Singer (1984). We estimate the model with $M=1$ (no unobserved heterogeneity), $M=2$, and $M=3$, and chose an "optimal" $M$ according to the Schwarz Bayesian information criterion (e.g., Stock and Watson 2003).

Because $0 \leq p_{l m} \leq 1(m=1, \cdots, M)$, for computational convenience we represent $p_{l m}$ 's in terms of $q_{l m}$ 's as follows:

$$
p_{l m}=\frac{e^{q_{l m}}}{\sum_{l=1}^{M} \sum_{m=1}^{M} e^{q_{l m}}}, \quad l, m=1, \cdots, M
$$

The advantage of this representation is that $q_{l m}$ is not bounded, $-\infty<q_{l m}<\infty$. Of course, $\sum_{l=1}^{M} \sum_{m=1}^{M} p_{l m}=1$, so normalization is necessary, and we choose to impose $q_{11}=0$.

Some normalization is also required to estimate the overall level of each hazard rate, as the "intercepts" in the baseline hazard rates, the constant terms in $x$ and $z$, and the unobserved heterogeneity terms ( $e$ and $v$ ) are redundant if left unrestricted. We use the baseline hazard function to estimate the overall level of each hazard rate, and impose restrictions on the other two "intercepts", by excluding the constant term from both $x$ and $z$ and setting $e_{1}=v_{1}=0$.

By taking the expectation with respect to $e$ and $v$, one derives

$$
\begin{aligned}
& \operatorname{Pr}\left(t-1<T_{r} \leq t, T_{j}>t-1\right)=E_{e, v} \operatorname{Pr}\left(t-1<T_{r} \leq t, T_{j}>t-1 \mid z, e, v\right) \\
= & \sum_{l=1}^{M} \sum_{m=1}^{M} p_{l m}\left[S_{r}\left(t-1 \mid z, e_{l}\right)-S_{r}\left(t \mid z, e_{l}\right)\right] S_{j}\left(t-1 \mid z, v_{m}\right), \\
& \operatorname{Pr}\left(T_{r}>t-1, t-1<T_{j} \leq t\right)=E_{e, v} \operatorname{Pr}\left(T_{r}>t-1, t-1<T_{j} \leq t \mid z, e, v\right) \\
= & \sum_{l=1}^{M} \sum_{m=1}^{M} p_{l m} S_{r}\left(t-1 \mid z, e_{l}\right)\left[S_{j}\left(t-1 \mid z, v_{m}\right)-S_{j}\left(t \mid z, v_{m}\right)\right], \\
& \operatorname{Pr}\left(T_{r}>t, T_{j}>t \mid z\right)=E_{e, v} \operatorname{Pr}\left(T_{r}>t, T_{j}>t \mid z, e, v\right) \\
= & \sum_{l=1}^{M} \sum_{m=1}^{M} p_{l m} S_{r}\left(t \mid z, e_{l}\right) S_{j}\left(t \mid z, v_{m}\right) .
\end{aligned}
$$

These unconditional (with respect to $e$ and $v$ ) probabilities will form our likelihood function. The resulting likelihood function will be a function of $\beta, \gamma, a, r_{k}$ 's, $j_{k}$ 's, $e_{l}$ 's, $v_{m}$ 's, and $q_{l m}$ 's, with the normalizations $e_{1}=0, v_{1}=0$, and $q_{11}=0$.

To summarize, the recall hazard rate and the new job hazard rate are related through two channels: (i) individual optimization implies a behavioral relationship across time and across individuals, as predicted by the search model; and (ii) heterogeneity across individuals and jobs may induce a non-behavioral relationship 
directly. The first channel will be captured by the sign of $a$. We expect $a$ to be negative, implying that when the recall hazard rate is lower, due either to the passage of time since the lay-off or to individual or job characteristics, the new job hazard rate is higher as the worker adjusts his new job search behavior. The second channel, individual heterogeneity, will be captured in two ways. For measured heterogeneity $z$, we allow differential impacts of numerous individual covariates in the two hazards: $\beta$ and $\gamma$ are not restricted to be equal for the variables in $x$. For unmeasured heterogeneity, we model $(e, v)$ as following a general discrete bivariate distribution, which allows unmeasured heterogeneity to affect the two hazards differently. If the type of person who is more likely to be recalled to his previous job is also likely to find a new job faster for reasons not related to his optimal new job search strategy, holding measured heterogeneity constant, then we would expect $e$ and $v$ to be positively correlated. (Recall that using a different approach, assuming a bivariate log-normal distribution, Han and Hausman found a positive, but statistically insignificant, relationship.)

Once we estimate the model, we will be interested in (i) the temporal patterns in $r_{k}$ 's and $j_{k}$ 's, that is, duration dependence, (ii) the behavioral relationship between $r(t \mid x, e)$ and $j(t \mid z, v)$, that is, the coefficient $a$, (iii) the relationship between $\beta$ and $\gamma$, and (iv) the joint distribution of $e$ and $v$, (including the "optimal" value for $M$ ).

Before moving on to describe the data, we note that an alternative empirical strategy would be to control for the direct effects of heterogeneity in estimating the recall and new job hazards, but to attempt to avoid confusing the spurious and behavioral relationships between the two hazards by estimating the influence of changes in the recall hazard on the new job hazard rate only over the course of an unemployment spell, while leaving aside the influence on the new job hazard of differences from person to person in recall hazard schedules.

In work not reported here, we pursued this strategy. That is, we estimated a model in which only the baseline recall hazard rate, stripped of all heterogeneity terms, can influence the new job hazard rate directly via the behavioral term (the term that takes the coefficient $a$ ). The estimates described a negative behavioral relationship between the two hazards over the course of a spell of unemployment. However, the finding was fragile, and not statistically significant at conventional levels. We attribute this to not having enough variation over time in recall hazard rates to allow us to convincingly identify the behavioral negative relationship by looking at the time-variation alone. One has to make use of the cross-sectional variation as well.

\section{Data}

Our data are drawn from Waves XIV, XV, and XVI (interview years 1981-83) of the Panel Study of Income Dynamics (PSID), the same source used by Katz (1986), Han and Hausman (1990), and Idson and Valletta (1996). Our sample comprises 
heads of households who lost a job due to plant closings, the end of seasonal or temporary jobs, or because they were "laid off" (either permanently or temporarily) or fired. Each observation refers to the last spell of unemployment experienced during the year previous to the interview, or else to a spell of unemployment that was ongoing at the time of the interview. Specifically, those who were employed or on temporary layoff at the time of the interview were asked, referring to their last spell of unemployment in the calendar year previous to the interview, "How many weeks was it before you returned to work?" They were then asked whether that spell of unemployment ended by returning to the same employer. Answers to these two questions allow us to assign a value to the unemployment duration, and to distinguish between spells leading to recalls and spells leading to new jobs. ${ }^{3}$

Those who were unemployed (and not on temporary layoff) at the time of the interview were asked "How long have you been looking for work?" When available, we used the answers to these questions as the spell durations which are rightcensored. In the case of those still on temporary layoff at the date of the interview, however, durations were typically approximated by subtracting the reported month in which the spell began from the interview month. ${ }^{4}$

We further restricted the sample to people who were between 21 and 64 years of age at the time of the interview, who were in the labor force every year from 1980 to 1983 and were not exclusively self-employed during those years, and to observations that were not missing data for any of the variables described below. We artificially censored spells at 60 weeks of unemployment: any observations with reported durations of 60 weeks or more were treated as still unemployed after 59 weeks. In addition, the questions do not allow us to identify with confidence spells with durations of zero weeks. Therefore, we retain in the sample only unemployment spells that are reported to have lasted at least 1 week, and renormalized all the durations so that, for computational purposes, they span 0 to 59 weeks. Thus, the estimated hazard for the first week really refers to the hazard for the second week, and so on.

In the end, we were left with a sample of 1403 observations, 274 of which ended in a new job, 718 of which ended in a recall (that is, a return to the same employer), and 411 of which were still unemployed (censored) at the time of the survey or were artificially censored at 59 weeks. Of the total of 1403 observations, 156 began with a plant closing or a temporary or seasonal job ending, and are accordingly assumed to have recall hazard rates of zero throughout the spell. ${ }^{5}$

3 Since those on temporary layoff at the time of the interview may have completed the last spell of unemployment in the previous year, they are not necessarily on temporary layoff for the purposes of our sample.

4 The nature of the questions is such that, in some cases, the reason for the separation (which we used to distinguish job losses from quits) may not refer to the same episode that generated the recorded spell of unemployment. This is not likely to be often true, but does add some uncertainty to our results.

5 In practice, the spell of unemployment whose cause the survey identifies is 
The explanatory variables are as follows. All but "temp/seasonal job ended" and "plant closed" appearing in both hazard functions. That is, $z$ includes all the variables below, whereas $x$ includes all the variables other than "tempseas" and "closed", which enter the recall hazard only through the "nohope" variable. The industry and occupation variables refer to the job that was lost.

SOCIO-ECONOMIC VARIABLES:

age (at time of interview, in years)

male ( $=1$ if male, $=0$ if female)

education (years of schooling at time of interview)

white $(=1$ if white, $=$ zero otherwise)

UI benefit ( $=1$ if received UI benefits during spell, $=0$ otherwise)

married ( $=1$ if married at time of interview, $=0$ otherwise)

county unemployment rate (unemployment rate in county of residence)

home ownerwhip (= 1 if owns own home, $=0$ otherwise)

veteran $(=1$ if a veteran, $=0$ otherwise)

spouse employed ( $=1$ if spouse had a job at interview date, $=0$ otherwise)

YEAR DUMMY VARIABLES:

$\mathrm{y} 82=1$ if wave XV (1982 interview year $),=0$ otherwise

y83 = 1 if wave XVI (1983 interview year $),=0$ otherwise

VARIABLES DESCRIBING LOST JOB

plant closed ( $=1$ if plant closed, $=0$ otherwise)

temp/seasonal job ended ( $=1$ temporary or seasonal job ended, $=0$ otherwise)

union member $(=1$ if member of a union, $=0$ otherwise)

job tenure (years at the lost job)

REGION DUMMY VARIABLES:

northeast (resided in the Northeast in previous year)

northcentral (resided in the North Central in previous year)

south (resided in the South in previous year)

INDUSTRY DUMMY VARIABLES:

finance/insurance/realtor (includes several other service industries)

trans/comm/utility (transportation, communications, utilities)

construction

durable manufacturing

mining

not necessarily the last spell of unemployment in the calendar year previous to the interview (the latter being the spell to which the duration measures refer). As a consequence, a small number of observations who reported a plant closing or a temporary or seasonal job ending also reported having returned to the same employer following the last spell in the previous year. We coded such observations as normal layoffs since the answers given probably referred to different spells. 
nondurable manuracturing

retail/wholesale (retail or wholesale trade)

(The omitted category includes agriculture, forestry, fisheries, recreation and personal services.)

OCCUPATION DUMMY VARIABLES:

managment/admin (management, administration)

clerical/sales/service

craft

operatives

professional/technical

(The omitted category includes laborers and farm occupations.)

Table 1 shows the sample mean and the sample standard deviation of each explanatory variable used in the paper.

(Table 1 here.)

\section{Results}

As we have emphasized so far, adequate controls for heterogeneity are important for testing the behavioral implications of search theory using data on single unemployment spells for many individuals. We assume that $u$ and $v$ follow a discrete bivariate distribution with the same number of points of support for each term. We experimented with 1, 2, 3, and 4 points of support. Some unobserved heterogeneity is clearly indicated. The Schwarz Bayesian information criterion strongly recommends 2 points of support (SBIC $=-4093$ vs. -4213 for 3 points), while the the Akaike information criterion is indifferent between 2 and 3 points. Adding a fourth point of support to each hazard's heterogeneity term improved the log-likelihood trivially. Accordingly, we will feature the estimates from the mixed proportional hazard model allowing for two points of support of unmeasured heterogeneity, shown in table 2. The values for $e_{1}$ and $v_{1}$ are normalized to zero, and the signficicance of the $e_{2}$ and $v_{2}$ terms attests to the importance of unobserved heterogeneity.

We tested the validity of the proportional hazard assumption using the method suggested by Ryu (1994). That is, one can test the proportionality assumption by testing the equivalence of two sets of estimates, one estimated using the original weekly duration data and the other estimated using a more aggregated version of the same duration data. In our case, we aggregated the unemployment duration data according to the baseline steps). According to the joint chi-square test, we cannot reject the proportionality assumption. Judging by individual t-tests, only the local unemployment rate (ructy) turns out to have a non-proportional impacts on the new job hazard rates. It significantly depresses the new job hazard rates at an earlier period after lay-off. But such an effect dies out over time, generating 
non-proportionality. We cannot reject proportionality for any other coefficients. ${ }^{6}$

(Table 2 here.)

Among the explanatory variables, note that membership in a union increases the recall hazard while decreasing the new job hazard. ${ }^{7}$ Job tenure significantly increases the recall hazard rates whereas its impact on the new job hazard rates is negative but not statistically significant.

Note also that having lost one's job due to a plant closing has a significant positive effect on the new job hazard rate. But, having lost one's job due to ending of a seasonal or temporary job - a variable that has often appeared as having a positive influence on new job finding in the literature - is not estimated to have a significant effect on the new job hazard rate. This would not imply that those displaced by ending of seasonal or temporary jobs behave no differently than those laid-off for other reasons, however. They all have zero recall chances (by assumption), and this affects their new job hazards so long as the coefficient $a$ is not zero.

By comparing estimated coefficients for each of the individual covariates in the recall and new job hazard functions, we observe that with respect to several characteristics (namely, sex, race, UI recipiency, and geography), people who are faster to find new jobs are also faster to be recalled, a "spurious" positive relationship between the two hazard rates arising from heterogeneity alone. This contrasts with the estimated effects of union membership, job tenure, and plant closings, which, as noted above, have opposite signs for the two hazards.

The model included interactions for UI receipt at weeks 26 and 39. The usual spikes seen at the UI benefit exhaustion points (26th and 39th weeks) are confirmed by the positive coefficient estimates of the UI interaction terms at 26 and 39 weeks (coefficients ui26 and ui39), the first two of which are significantly positive.

In this model, the behavioral coefficient $a$ is estimated to be significantly negative, but small. A sense of the size of this estimated effect of the prospect for recall on new-job finding can be gathered from graphs 1 and 2. The graphs present the recall and new job hazard rates in percentage terms (after exponentiating the log hazard rates), at the mean of the explanatory variables. The solid line in graph 2 shows how the estimated new job hazard changes over the course of a spell of unemployment for an individual with no chance of recall at any time (that is, $1_{\text {nohope }}=1$ ). The dashed line shows how the estimated new job hazard changes over a spell for an individual with the estimated recall hazard depicted in Graph 1. The difference between the lines reflects our esitmate of $a$.

Graphs 1 and 2 here.

6 Detailed test results are available upon request.

7 This is the direct effect of union membership on the new job hazard rate; union membership may also affect the new job hazard indirectly by raising the recall hazard, but this is manifested exclusively through the behavioral coefficient $a$. 
The importance of our treatment of unobserved heterogeneity for this result is demonstrated in Table 3. The table shows the estimates of the behavioral coefficient for the 4 different specifications that allow for successively greater degrees of unobserved heterogeneity by allowing successively more points of support for its discrete distribution.

\section{(Table 3 here.)}

In the specification with just 1 point of support for the unobserved heterogeneity term, which is to say, the specification that assumes no unobserved heterogeneity, the estimate of the $a$ coefficient is far more negative than in those specifications wherein unmeasured heterogeneity is taken into account. While once some unobserved heterogeneity is allowed (i.e., at least 2 points of support), the estimate is not very sensitive to the the number of support points assumed. ${ }^{8}$

All in all, while our empirical results support the prediction of the theory that there should be a negative behavioral relationship between the recall and the new job hazard rates, but the estimated correlation is not large.

Clearly, then, one must adequately control for both measured and unmeasured heterogeneity in order to identify the behavioral relationship between these two avenues for leaving unemployment. Drawing general inferences about behavior from data on single spells of many heterogeneous individuals is a challenging task, and we do not doubt that better data are likely to be more useful than better econometric techniques for estimating the theoretical implications of job search models, a situation familiar to researchers in many areas. (For example, see Lalonde 1986 on evaluating the effectiveness of job training programs.) Nevertheless, we obtain empirical results consistent with the theoretical predictions by applying econometric tools to the sort of less-than-ideal data with which one is most often confronted. The sensitivity of our findings to the introduction of unobserved heterogeneity, and their robustness to varying the degree of unobserved heterogeneity gives us confidence that our procedure was adequate to the task.

Graphs 1 and 2 also indicate that we find limited duration dependence in the hazard rates. The estimated recall hazard rate exhibits negative duration dependence, as posited in our theoretical model and documented by previous researchers. However, the recall hazard rate only begins to decline after about 6 months following a lay-off; the rate is flat, or even increasing, over the first 6 months of unemployment. This suggests that it would be very difficult to identify the behavioral influence of recall chances on the new job hazard by looking at the relationship over time alone. Cross-sectional variation is critical.

The new job hazard rate is more or less increasing over the course of the unemployment spell, but not uniformly so.

8 We were unable to estimate the standard error of the coefficient in the case with four points of support. 


\section{Our Estimates compared to Katz and Meyer's}

Except in the case where only observed heterogeneity is modeled, our estimate of the behavioral impact of recall prospects on the new job hazard appears to be considerably smaller than that reported in Katz and Meyer (1990; KM hereafter) or Anderson (1992). However, comparing the estimates is not straightforward. Recall that KM's measure of recall expectations is a zero-one indicator variable for expecting recall or not expecting recall. According to KM's estimates, a person who "expects recall" has a new job hazard rate that is $60 \%$ to $75 \%$ as large as a person who does not expect recall. But it is not clear just what it means to "expect recall" in this context. Neither the likelihood of recall nor the time frame is specified. ${ }^{9}$ In addition, our model deals with a recall hazard rate rather than an indicator variable. For both reasons, comparing our estimates to theirs is best done by example. And the task is made easier by positing constant recall hazard rates.

According to our estimates, a reduction in the new job hazard similar in size to that found by KM for someone expecting recall relative to someone not expecting recall would arise from a constant recall hazard rate of $40 \%$ to $50 \%$ relative to a recall hazard rate of zero (that is, to having no recall prospects at all, such as would be true if nohope $=1$ ). But how well does a recall hazard rate of $40 \%$ to $50 \%$ correspond to "expecting recall"? One way to guage this is that a constant recall hazard rate of this magnitude would imply that an individual has a $99 \%$ chance of having been recalled by 6-10 weeks of unemployment, with a mean timeuntil-recall of 2 to $2-1 / 2$ weeks. If this is a good description of the typical recall prospect faced by someone who "expects recall" at the time of the layoff, then our estimates are of a similar magnitude to KM's. As an alternative, if one thinks that someone "expecting recall" at the time of the layoff corresponds better to his having, say, a $99 \%$ chance of being recalled within a year and a mean time-until recall of 10 weeks, then a better comparision would be with an individual with a constant recall hazard rate of $10 \%$. According to our estimates, such an individual would have a new job hazard that is $92 \%$ as large as a person with no prospects for recall, a considerably smaller difference than that estimated by KM, although still enough to raise a person's mean time-until-new-job by $9 \%$.

How can we reconcile our results with those of KM? If we ourselves were asking the survey question in KM's data, we would have in mind a recall hazard rate more in the neighborhood of $10 \%$ than $50 \%$ when we asked whether the respondent expects to be recalled. In this case, we would interpret our estimate of the behavioral response to those expectations of recall as being much smaller than KM's. However, the survey respondents may have a higher probability or different time frame in mind. In particular, workers who expect recall may be overly optimistic, reacting to an "ex ante" subjective recall hazard rate that is larger than the "ex post"

9 The survey questions is "do you expect to be called back to work by any of your past employers?" (KM, p. 978). 
realized hazard rate that we estimate. If this is the explanation, it suggests that laid-off workers would increase their search efforts if they were made better aware of their true prospects for recall. Of course, we may simply not have done a good job of estimating the ex post recall hazard rate. But note that in KM's data and especially in Anderson, a substantially greater fraction of persons initially expected recall than ended up being recalled.

Another possibility is the treatment of unobserved heterogeneity. KM assume that unobserved heterogeneity is distributed according to a gamma distribution and that it is independent across risks. They found that their results were not very sensitive to whether or not they controlled for unobserved heterogeneity or not. But perhaps those assumptions are overly restrictive. In the current study, we assume that unobserved heterogeneity has a discrete distribution, which Heckman and Singer (1984) argue is better than the gamma assumption. We also allow the unobserved heterogeneity to be correlated across the two risks. In sharp contrast to KM's results, we found that the estimate of the influence of the recall hazard on the new job hazard rate is 10 times larger when we do not control for unobserved heterogeneity as when we do (table 2). This may be due to our less restrictive assumptions. ${ }^{10}$ If so, then officials designing programs for laid-off workers need not be particularly concerned that job search assistance, for example, would be wasted on those on temporary layoff.

\section{Concluding Remarks}

In this paper, we derive theoretically a negative behavioral relationship between recall hazard rates and new job hazard rates. In order to identify the behavioral relationship separately from the spurious relationship induced by individual heterogeneity, we use theoretical implications as identifying restrictions and try to control adequately for both observed and unobserved heterogeneity. We find evidence of a negative behavioral relationship between the recall and new job hazards. Although comparisons are not straightforward, the estimated relationship in this paper appears to be much weaker than that reported in Katz and Meyer (1990) or Anderson (1992), raising questions about its true magnitude, and highlighting the likelihood that laid-off workers tend to hold unrealistically optimistic views of their chances for recall. If so, then policy might be well directed towards encouraging employers to give their employees a better idea of their prospects for recall, perhaps by providing

\footnotetext{
10 It is also possible that KM do not find unobserved heterogeneity to be important because their sample is less heterogeneous than ours to begin with. However, this is not entirely clear. On the one hand, KM's sample comprises only UI recipients, which would make it less heterogeneous, and comes from administrative data that may include less measurement error that could create artificial heterogeneity in the data. On the other hand, our sample includes only heads of households (as defined by the PSID).
} 
a record of the quantity and spped of recalls during past episodes of layoffs.

In addition, we find positive duration dependence in the new job hazard, and some negative duration dependence in the recall hazard, once heterogeneity has been accounted for. However, to our surprise, we find no indication that the recall hazard rate declines over the first six months of an unemployment spell.

The current analysis suggests at least two avenues for further work on this topic. One would be to include multiple spells per individual in the analysis, presumably using a richer source of data. Another would be to attempt a fully structural approach to estimating the duration model. This would involve (i) specification of $F(w)$ and $\lambda(s)$, and (ii) characterization of $s(r)$ and $w_{r}^{*}$ in terms of $r$, which would require solving the value function using numerical techniques. These and other possibilities are left for future research. 


\section{Appendix: Proof of Theorems 1 and 2}

When the two unemployed workers A and B in theorem 2 face the same environment in terms of new job arrival rates, offered wage distribution, and search costs - that is, if they are identical in all respects except their recall hazard rates - then the proofs of theorem 1 and 2 are virtually the same. It suffices to prove that a lower recall hazard rate leads one to search for new job more intensely. If a lower recall hazard rate corresponds to a later time in a spell of unemployment spell for a single unemployed worker, then the proof covers theorem 1, whereas if a lower recall hazard rate applies to one individual faced with a lower recall hazard than another individual, then it covers theorem 2. So, the following proof applies to both theorems.

Let $Q(r)$ be the expected discounted future income over $[0, \infty)$ when the current recall hazard rate is $r$ and when the laid-off worker follows the optimal search strategy. This $Q(r)$ represents the value of optimal search strategy as a function of the current recall hazard rate, the so-called value function.

Using Bellman's optimality principle, we can write $Q(r)$ as:

$$
\begin{aligned}
Q(r) & =\max _{s \in S}\left[-c(s) d t+e^{-\delta d t}\{r d t \cdot w / \delta\right. \\
& \left.\left.+(1-r d t)\left[\lambda(s) d t E\left[\max \left(W_{j} / \delta, Q\left(r-b_{r} d t\right)\right)\right]+(1-\lambda(s) d t) Q\left(r-b_{r} d t\right)\right]\right\}\right] \\
& =\max _{s \in S}\left[-c(s) d t+e^{-\delta d t}\{r d t \cdot w / \delta\right. \\
& \left.\left.+(1-r d t)\left[Q\left(r-b_{r} d t\right)+\lambda(s) d t \cdot \int_{w_{r}^{*}}^{\infty}\left(w / \delta-Q\left(r-b_{r} d t\right)\right) d F(w)\right]\right\}\right],
\end{aligned}
$$

where $w_{r}^{*}$ is determined from $w_{r}^{*} / \delta=Q\left(r-b_{r} d t\right)$ and $b_{r}$ is defined as $b_{r}=|\partial r(t) / \partial t|$ evaluated at $t=r^{-1}(r)$.

Note that the infinite future $[0, \infty)$ is divided into the immediate future $[0, d t)$ and the rest of time $[d t, \infty)$. Under this decomposition, we can interpret each term on the right hand side of the above value function as follows. When the search effort is $s$, the worker incurs the search cost $c(s) d t$ over the interval $[0, d t)$. The value in the rest of the future $[d t, d t+\infty)$ is determined differently according to whether or not the worker receives notice of recall during the interval $[0, d t)$. If he receives recall notice (which happens with probability $r d t$ ), he will accept recall and the resulting value is $w / \delta$. If he does not receive recall notice, which happens with probability $1-r d t$, his choice of action depends on whether he receives a new job offer (happening with probability $\lambda(s) d t$ ) or not (happening with probability $1-\lambda(s) d t)$. When he has a new job offer in hand, he will compare the expected discounted future income from the new job, $W_{j} / \delta$, with the value of continuing search under a reduced recall hazard rate, $Q\left(r-b_{r} d t\right)$. When he has not received a new job offer, his future value of search is just $Q\left(r-b_{r} d t\right)$.

By using the facts (i) $e^{-\delta d t}=1-\delta d t+o(d t)$, where $X=o(d t)$ if $\lim _{d t \rightarrow 0} X / d t=$ 
0, (ii) $Q\left(r-b_{r} d t\right)=Q(r)-b_{r} Q^{\prime}(r) d t+o(d t)$, and (iii) the monotonicity of $Q(r)$, $Q^{\prime}(r) \geq 0$, we can express the above value function as follows:

$$
\begin{gathered}
Q(r)=o(d t)+\max _{s \in S}[-c(s) d t+(1-\delta d t)\{r d t \cdot w / \delta \\
\left.\left.+(1-r d t)\left[Q(r)-b_{r} Q^{\prime}(r) d t+\lambda(s) d t \int_{w_{r}^{*}}^{\infty}\left(w / \delta-Q(r)+b_{r} Q^{\prime}(r) d t\right) d F(w)\right]\right\}\right] .
\end{gathered}
$$

After dividing both hand sides of (2) by $d t$ and letting $d t \rightarrow 0$, we have:

$$
0=\max _{s \in S}\left[-c(s)+r w / \delta-(r+\delta) Q(r)-b_{r} Q^{\prime}(r)+\lambda(s) \int_{w_{r}^{*}}^{\infty}(w / \delta-Q(r)) d F(w)\right]
$$

By taking derivative of the right hand side of (3) with respect to the search intensity $s$, one has:

$$
0=-c^{\prime}(s)+\lambda^{\prime}(s) \int_{w_{r}^{*}}^{\infty}(w / \delta-Q(r)) d F(w)
$$

where $w_{r}^{*}$ is determined from $w_{r}^{*} / \delta=Q(r)$. That is, $w_{r}^{*}=\delta Q(r)$. If the first-order condition (4) is satisfied at a positive search intensity $s>0$, that solution is the optimal search intensity. On the other hand, no search will be optimal if

$$
c^{\prime}(0) \geq \lambda^{\prime}(0) \int_{w_{r}^{*}}^{\infty}(w / \delta-Q(r)) d F(w)
$$

Note that these necessary first-order conditions (4) and (4') for optimal search are in fact sufficient as well thanks to Assumption 4.

The condition (4') for the corner solution $(s=0)$ is more likely to be satisfied if the current recall hazard rate $r$ is high, and $w_{r}^{*}$ is consequently large. Let $r^{*}$ be the threshold level of the recall hazard rate such that if the current recall hazard rate is higher than $r^{*}$ it is optimal not to search at all, and otherwise it is optimal to search. Obviously, $r^{*}$ will be determined as a solution to (4') when the inequality is replaced by an equality.

Since $w_{r}^{*}=\delta Q(r)$, we have $\partial w_{r}^{*} / \partial r=\delta Q^{\prime}(r)>0$, which implies that as the recall hazard rate is lower the reservation wage is lower as well. The recall hazard rate can be lower due to the passage of time for an individual unemployed worker, or due to inferior individual characteristics when comparing two workers at the same time.

For the interior solution case $\left(r \leq r^{*}\right)$, the first order condition (4) equates the marginal benefit of search intensity, $\lambda^{\prime}(s) \int_{w_{r}^{*}}^{\infty}(w / \delta-Q(r)) d F(w)$, with the marginal cost of search intensity, $c^{\prime}(s)$. 
Let the solution be $s(r)$. One can easily see that as $r$ decreases, the optimal search intensity increases, implying that $s(r)$ is decreasing in $r$. By plugging in the optimal search intensity $s(r)$ back into (3), one derives:

$$
Q(r)=\frac{-c(s(r))+r w / \delta-b_{r} Q^{\prime}(r)+\lambda(s(r)) \int_{w_{r}^{*}}^{\infty} w / \delta d F(w)}{r+\delta+\lambda(s(r))\left[1-F\left(w_{r}^{*}\right)\right]} .
$$

Consider the case where $r>r^{*}$. When the recall hazard rate is sufficiently high, it is optimal not to search for a new job at all: $s=0$, a corner solution. In this case, the laid-off worker just waits to be recalled without paying any search cost, $c(0)=0$, and receives new job offers at the minimum possible rate, $\lambda(0)$. Using these observations, we have from (5)

$$
Q(r)=\frac{r w / \delta-b_{r} Q^{\prime}(r)+\lambda(0) \int_{w_{r}^{*}}^{\infty} w / \delta d F(W)}{r+\delta+\lambda(0)\left[1-F\left(w_{r}^{*}\right)\right]}, \text { for } r>r^{*} .
$$

Now consider the case where $r=0$. Once the recall hazard rate hits zero, it can decline no further and the problem becomes stationary. This corresponds to the Lippman and McCall type traditional job search model under stationarity. Note that $Q^{\prime}(0)=0$, or, more precisely, $Q\left(0-b_{0} d t\right)=Q(0)$ (since $\left.b_{0}=0\right)$. Therefore,

$$
0=-c^{\prime}(s)+\lambda^{\prime}(s) \int_{w_{0}^{*}}^{\infty}(w / \delta-Q(0)) d F(w),
$$

And

$$
Q(0)=\frac{-c(s(0))+\lambda(s(0)) \int_{w_{0}^{*}}^{\infty} w / \delta d F(w)}{\delta+\lambda(s(0))\left[1-F\left(w_{0}^{*}\right)\right]} .
$$

We can interpret $Q(0)=w_{0}^{*} / \delta$ as the value of permanent lay-off. In our empirical implementation, this value applies to those workers who lost their jobs due to plant closing or end of seasonal or temporary jobs, for whom we assume that no recall is possible.

From the above discussions, we reach the following conclusions regarding the hazard rate for terminating the unemployment spell by taking a new job, viewed as a function of the recall hazard rate. Let us denote the function by $j(r)$. This hazard rate is a product of the new job arrival rate and the probability that the offered wage exceeds the reservation wage: $j(r)=\lambda(s(r)) \cdot\left[1-F\left(w_{r}^{*}\right)\right]$. Since $\lambda^{\prime}(s)>0, s^{\prime}(r) \leq 0$, and $\partial w_{r}^{*} / \partial r>0$, we have $j^{\prime}(r) \leq 0$. That is, the new job hazard rate is increasing as the recall hazard rate decreases. This behavioral negative relationship holds both across time for an individual unemployed worker (Theorem 1) and across different workers at the same time (Theorem 2). 


\section{References}

Anderson, P. (1992), "Time-varying Effects of Recall Expectation, a Reemployment Bonus, and Job Counseling on Unemployment Durations," Journal of Labor Economics, 10, 99-115.

Fallick, B. (1991), "Unemployment Insurance and the Re-employment of Displaced Workers," Review of Economics and Statistics, 73, 228-235.

Han, A. K., and Hausman, J. A. (1990), "Flexible Parametric Estimation of Duration and Competing Risk Models," Journal of Applied Econometrics, $5,1-28$.

Heckman, J., and Singer, B. (1984), "A Method for Minimizing the Impact of Distributional Assumptions in Econometric Models for Duration Data," Econometrica, 52, 271-320.

Idson, Todd L. and Robert G. Valletta (1996), "Seniority, Sectoral Decline, and Employee Retention: An Analysis of Layoff Unemployment Spells," Journal of Labor Economics, 14, 654-76.

Katz, L. (1986), "Layoffs, Recall and the Duration of Unemployment," Working Paper No. 1825, NBER, Cambridge, Massachusetts.

Katz, L., and B. Meyer (1990), "Unemployment Insurance, Recall Expectations, and Unemployment Outcomes," Quarterly Journal of Economics, 105, 973-1002.

LaLonde, R. (1986), "Evaluating the Econometric Evaluations of Training Programs with Experimental data," American Economic Review, 76, 604-620.

Lippman, S., and J. McCall (1976a), "The Economics of Job Search: A Survey," Economic Inquiry, 14, 155-89 and 347-68.

Lippman, S., and J. McCall (1976b), "The Economics of Job Search: A Survey: Part I," Economic Inquiry, 14, 155-189.

McCall, B. (1996), "Unemployment Insurance Rules, Joblessness, and Part-time Work," Econometrica, 64, 647-682.

Pichelmann, K., and M. Riedel (1992), "New Jobs or Recalls? Flow Dynamics in Austrian Unemployment Reconsidered," Empirica - Austrian Economic Papers, 19, 259-74.

Ryu, K. (1994), "Group Duration Analysis of the Proportional Hazard Model: Minimum Chi-square Estimators and Specification Tests," Journal of the American Statistical Association, 89.

Stock, J. and M. Watson (2003), Introduction to Econometrics, Addison Wesley. Sueyoshi, G. (1992), "Semi-parametric Proportional Hazards Estimation of Competing Risks Models with Time-varying Covariates," Journal of Econometrics, 51, 25-58. 
Table 1. Selected Statistics of the Sample

\begin{tabular}{|c|c|c|}
\hline variable name & mean & SD \\
\hline age & 34.90 & 10.76 \\
male & 0.85 & 0.36 \\
education & 11.35 & 2.24 \\
white & 0.54 & 0.50 \\
UI benefit & 0.66 & 0.47 \\
married & 0.69 & 0.46 \\
county unemployment rate & 9.52 & 3.82 \\
home ownership & 0.49 & 0.50 \\
veteran & 0.25 & 0.43 \\
spouse employed & 0.38 & 0.49 \\
union member & 0.41 & 0.49 \\
job tenure & 49.36 & 68.46 \\
northeast & 0.12 & 0.33 \\
north central & 0.28 & 0.45 \\
south & 0.44 & 0.50 \\
finanace/insurance/realtor & 0.10 & 0.31 \\
trans/comm/utility & 0.07 & 0.26 \\
construction & 0.15 & 0.35 \\
durable manufacture & 0.34 & 0.47 \\
mining & 0.03 & 0.17 \\
nondurable manufacture & 0.15 & 0.36 \\
retail/wholesale & 0.10 & 0.31 \\
management/admin & 0.04 & 0.21 \\
clerical/sales/service & 0.16 & 0.36 \\
crafts & 0.23 & 0.42 \\
operatives & 0.41 & 0.49 \\
professional/technical & 0.04 & 0.20 \\
closed & 0.08 & 0.27 \\
tempseas & 0.03 & 0.17 \\
\hline
\end{tabular}


Table 2. Estimates of Recall and New Job Hazard Rates

(each week in step $t: r(t)=e^{r_{t}+x \beta+e}$ and $j(t)=e^{j_{t}+z \gamma+a * e^{r_{t}+x \beta}+v}$ where the first three steps are each 2 weeks long, the second three 3 weeks long, the third three 4 weeks long, and the final three 11 weeks long.)

\begin{tabular}{|c|c|c|c|c|}
\hline TYPE & VARIABLE & PARAMETER & SE & T-VALUE \\
\hline recall & $\mathrm{r} 1$ & -0.70 & 0.602 & -1.15 \\
& $\mathrm{r} 2$ & -0.60 & 0.611 & -0.99 \\
& $\mathrm{r} 3$ & -0.89 & 0.618 & -1.44 \\
& $\mathrm{r} 4$ & -0.59 & 0.623 & -0.95 \\
& $\mathrm{r} 5$ & -0.63 & 0.639 & -0.99 \\
& $\mathrm{r} 6$ & 0.00 & 0.639 & 0.00 \\
& $\mathrm{r} 7$ & -0.61 & 0.661 & -0.92 \\
& $\mathrm{r} 8$ & -0.07 & 0.662 & -0.11 \\
& $\mathrm{r} 9$ & -0.35 & 0.714 & -0.49 \\
& $\mathrm{r} 10$ & -0.99 & 0.697 & -1.42 \\
& $\mathrm{r} 11$ & -1.19 & 0.822 & -1.45 \\
& $\mathrm{r} 12$ & -1.18 & 0.905 & -1.30 \\
& $\mathrm{y} 82$ & -0.43 & 0.155 & -2.77 \\
& $\mathrm{y} 83$ & -0.54 & 0.147 & -3.66 \\
\hline new job & $\mathrm{j} 1$ & -1.40 & 0.908 & -1.54 \\
& $\mathrm{j} 2$ & -0.89 & 0.943 & -0.94 \\
& $\mathrm{j} 3$ & -1.28 & 0.970 & -1.32 \\
& $\mathrm{j} 4$ & -1.02 & 0.950 & -1.07 \\
& $\mathrm{j} 5$ & -1.30 & 1.024 & -1.27 \\
& $\mathrm{j} 6$ & -0.63 & 1.026 & -0.61 \\
& $\mathrm{j} 7$ & -0.64 & 1.046 & -0.61 \\
& $\mathrm{j} 8$ & -1.32 & 1.116 & -1.18 \\
& $\mathrm{j} 9$ & -0.46 & 1.095 & -0.42 \\
& $\mathrm{j} 10$ & -0.47 & 1.135 & -0.41 \\
& $\mathrm{j} 11$ & -0.51 & 1.159 & -0.44 \\
& $\mathrm{j} 12$ & 0.48 & 1.228 & 0.39 \\
& $\mathrm{y} 82$ & -0.22 & 0.207 & -1.07 \\
& $\mathrm{y} 83$ & -0.75 & 0.208 & -3.60 \\
& $\mathrm{a}$ & -0.62 & 0.242 & -2.55 \\
\hline
\end{tabular}


Table 2. (continued)

\begin{tabular}{|c|c|c|c|c|}
\hline TYPE & VARIABLE & PARAMETER & SE & T-VALUE \\
\hline \multirow{7}{*}{} & $\mathrm{e} 1$ & 0.00 & & \\
& $\mathrm{e} 2$ & -3.28 & 0.195 & -16.85 \\
& $\mathrm{v} 1$ & 0.00 & & \\
& $\mathrm{v} 2$ & -1.70 & 0.486 & -3.49 \\
& & & & \\
& $\mathrm{q} 11$ & 0.00 & & \\
& $\mathrm{q} 12$ & -0.05 & 1.332 & -0.04 \\
& $\mathrm{q} 21$ & -0.23 & 0.700 & -0.33 \\
& $\mathrm{q} 22$ & 0.28 & 0.870 & 0.32 \\
\hline
\end{tabular}


Table 2. (continued)

\begin{tabular}{|c|c|c|c|c|}
\hline TYPE & VARIABLE & PARAMETER & $\mathrm{SE}$ & T-VALUE \\
\hline \multirow[t]{29}{*}{ recall $(\mathrm{x})$} & age & 0.005 & 0.007 & 0.71 \\
\hline & male & -0.482 & 0.239 & -2.01 \\
\hline & education & -0.021 & 0.030 & -0.72 \\
\hline & white & 0.639 & 0.133 & 4.80 \\
\hline & UI benefit & -0.842 & 0.139 & -6.06 \\
\hline & married & 0.168 & 0.202 & 0.83 \\
\hline & county unemployment rate & -0.014 & 0.015 & -0.90 \\
\hline & home ownership & 0.491 & 0.134 & 3.67 \\
\hline & veteran & -0.079 & 0.147 & -0.54 \\
\hline & spouse employed & -0.383 & 0.137 & -2.80 \\
\hline & union member & 0.680 & 0.134 & 5.07 \\
\hline & job tenure & 0.005 & 0.001 & 4.83 \\
\hline & northeast & -0.699 & 0.223 & -3.13 \\
\hline & north central & -0.487 & 0.197 & -2.47 \\
\hline & south & 0.047 & 0.192 & 0.25 \\
\hline & finanace/insurance/realtor & -1.486 & 0.397 & -3.74 \\
\hline & trans/comm/utility & -1.213 & 0.398 & -3.05 \\
\hline & construction & -0.462 & 0.350 & -1.32 \\
\hline & durable manufacture & 0.667 & 0.332 & 2.01 \\
\hline & mining & -0.740 & 0.483 & -1.53 \\
\hline & nondurable manufacture & 1.173 & 0.344 & 3.41 \\
\hline & retail/wholesale & -0.966 & 0.375 & -2.57 \\
\hline & management/admin & 0.067 & 0.380 & 0.18 \\
\hline & clerical/sales/service & -0.291 & 0.275 & -1.06 \\
\hline & crafts & 0.161 & 0.217 & 0.74 \\
\hline & operatives & -0.035 & 0.204 & -0.17 \\
\hline & professional/technical & -0.105 & 0.364 & -0.29 \\
\hline & UI26 & 1.75 & 0.398 & 4.40 \\
\hline & UI39 & 0.55 & 0.920 & 0.60 \\
\hline
\end{tabular}


Table 2. (continued)

\begin{tabular}{|c|c|c|c|c|}
\hline TYPE & VARIABLE & PARAMETER & $\mathrm{SE}$ & T-VALUE \\
\hline \multirow[t]{31}{*}{ new job $(z)$} & age & -0.035 & 0.010 & -3.43 \\
\hline & male & -0.480 & 0.307 & -1.57 \\
\hline & education & 0.061 & 0.041 & 1.49 \\
\hline & white & 0.856 & 0.196 & 4.37 \\
\hline & UI benefit & -0.648 & 0.192 & -3.38 \\
\hline & married & 0.330 & 0.247 & 1.34 \\
\hline & county unemployment rate & -0.048 & 0.026 & -1.82 \\
\hline & home ownership & 0.006 & 0.187 & 0.03 \\
\hline & veteran & 0.424 & 0.195 & 2.17 \\
\hline & spouse employed & 0.001 & 0.188 & 0.01 \\
\hline & union member & -0.386 & 0.203 & -1.90 \\
\hline & job tenure & -0.001 & 0.002 & -0.88 \\
\hline & northeast & -0.801 & 0.289 & -2.78 \\
\hline & north central & -1.092 & 0.285 & -3.83 \\
\hline & south & -0.367 & 0.218 & -1.68 \\
\hline & finance/insurance/realtor & -0.080 & 0.413 & -0.19 \\
\hline & trans/comm/utility & -0.547 & 0.439 & -1.24 \\
\hline & construction & 0.166 & 0.400 & -0.42 \\
\hline & durable manufacture & -0.524 & 0.402 & -1.30 \\
\hline & mining & -0.554 & 0.539 & -1.03 \\
\hline & nondurable manufacture & -0.017 & 0.433 & -0.04 \\
\hline & retail/wholesale & -0.259 & 0.400 & -0.65 \\
\hline & management/admin & -0.072 & 0.375 & -0.19 \\
\hline & clerical/sales/service & -0.230 & 0.316 & -0.73 \\
\hline & crafts & 0.121 & 0.262 & 0.46 \\
\hline & operatives & -0.333 & 0.282 & -1.18 \\
\hline & professional/technical & 0.317 & 0.397 & 0.80 \\
\hline & plant closed & 0.462 & 0.263 & 1.76 \\
\hline & temp/seasonal job end & -0.227 & 0.390 & -0.58 \\
\hline & $\mathrm{UI} 26$ & 1.79 & 0.450 & 3.99 \\
\hline & UI39 & 1.93 & 0.712 & 1.31 \\
\hline
\end{tabular}


Table 3. How the Estimates of "a" Change for differing level of control for unobserved heterogeneity

\begin{tabular}{|c|c|c|c|}
\hline Unobserved Heterogeneity & Estimate of "a" & SE(a) & t-Value \\
\hline 1 & -7.09 & 3.06 & -2.32 \\
2 & -0.62 & 0.24 & -2.55 \\
3 & -0.77 & 0.65 & -1.17 \\
4 & -0.78 & & \\
\hline
\end{tabular}


Graph 1: Recall Hazard Rates

(heterogeneity controlled)

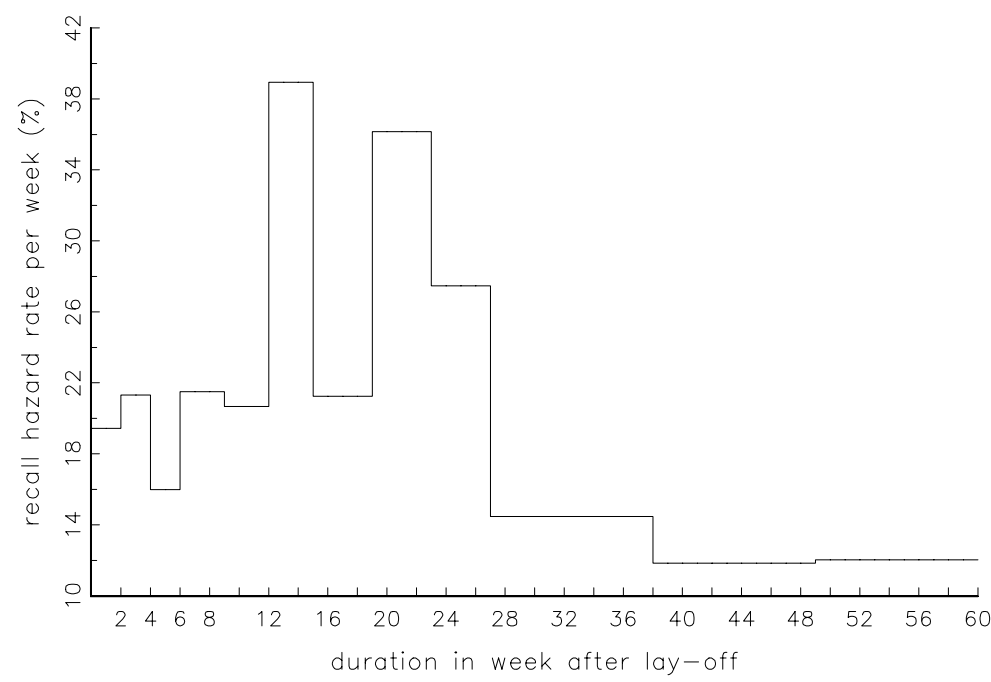

Graph 2: New Job Hazard Rates

(heterogeneity controlled)

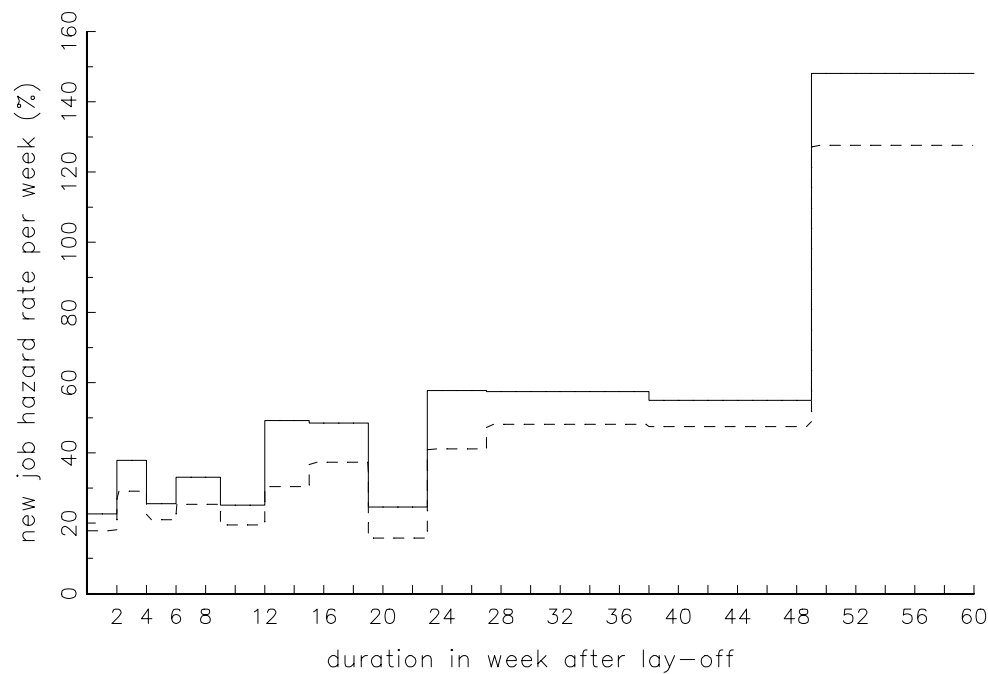

